\title{
Impact of Computer Music Technology on the Effect of the Information Memory of Audiences
}

\author{
Y. Qin, D.J. Li \\ Business College \\ Nankai University \\ Tianjin, 300071, China
}

\author{
Y. Qin, J.T. Yang \\ School of Management \\ Tianjin University of Traditional Chinese Medicine \\ Tianjin, 300193, China
}

\begin{abstract}
In the digital era to the core of computer technology, computer music came into being; it brings a series of new topics to disciplines to study. In the field of communication, the computer music technology is an element commonly used in the production of information, which can effectively achieve all kinds of information dissemination by the music computer synthesized. Through reviewing the recent research on computer music technology development and information dissemination effect, this paper analyzes the impact of computer music has on the audience memory in information dissemination.
\end{abstract}

Keywords-computer information technology; information production; communication effect

\section{INTRODUCTION}

Computer music is the product of combining development of science and technology and music and arts. When promoting social and economic development, science and technology can also improve the art form, content and communication vector, promote the application and development of computer music technology in different fields. Computer music technology is the especial computer application technology, the process of which is converting the musical sound information into machine-specific binary digital information and entering into the computer ,and such digital information will be processed via the specialized computer applications (music software),then the processing result is converted to voice information (computer music composition) and output to the viewers. Computer music technology includes the generation of digitized sound and digital real-time process of the sound two components, namely the so-called MIDI and digital audio technologies, which are the two core technologies of computer music. They both use the computer to process the information and produce the music, but they are two different technologies owning their special technical characteristics. With the development of these two types of technology, revolutionary changes have produced in various fields involving the use of music, and using computer technology to synthesize the song has become an important form commonly used in information production. Kilgour, Jakobson and Cuddy (2000) and other scholars are concerned about the effect of using computer music in advertising production, which confirmed that the memory effect is better to sing than to say expressing the same language content ${ }^{[1]}$. But some studies have shown that there is no difference of the effect whether using music technology or not, and even to sing has a worse memory effect than to say ${ }^{[2]}$.
For the confusion of the study, this paper based on the development of computer music technology background, analysis of computer music technology to consumers remember information relevant literature to explore the impact of information and communication computer electronic music effects. Faced with the confusion of the above studies, this paper analyzes of relevant literature about the effect of computer music technology on consumers memory information, based on the development of computer music technology background, to explore the impact of computer electronic music on the effects of information communication.

\section{History OF PRODUCtion AND DEVELOPMENT OF COMPUTER Music TECHNOLOGY}

Reviewing the entire development process of computer music technology, we have found that computer musical sound processing technology represented in the sequencer keeps the simultaneous development trend with computer musical sound producing technology and personal computer.

First, the generation of computer musical sound processing technology. Early in 1955, through special perforated roll tape, the first American-made synthesizer "RCA Electronic Music Synthesizer" can bring the sound with musical treatment in the manner of computing program. It was not until the 1980s, the computer music sound processing technology could be able to walk into the composer's studio and enter into the real practical stage with spread applications of the specially designed computer music Handler "Sequencer" on a Macintosh computer and PC Windows operating system.

Second, development of the computer music processing technology. With the advent of the low-cost personal computers in the early 1980s, in 1984,the American Passport company launched the first MIDI sequencer - Disings MIDI / 4 for personal computers in the history of computer musical development . The so-called sequencer is actually a music processing program for computer, which emerged as a landmark music creation tool with the development of the integrated circuit chip technology and the popularity of the personal computer. In addition to the general sensed sequencer software, in the last decade of the 20th century ,there appeared automatic orchestration software such as Band -in -a -Box, Jammer Pro dedicated to the creation of an accompaniment music, production of sheet music software (such as Sibelius, Finale, Encore, Overture) ,digital audio processing software (such as Cool Edit Pro, Sound Forge), multi-track audio 
synthesis software (such as Samplitude Producer 2496, Vegas Audio ), mastering software (such as T -Racks24), etc. The combination of the computer music applications software owning their different expertise with the traditional sequencer software has opened up a host of extremely broad application space for computer music sound processing technology.

\section{The ApPlication Of COMPUter Music TeChNOLOgY IN INFORMATION DISSEMINATION}

The advantage of computer technology is the ability to handle high level digital information, so the computer music is characterized by the digital processing of sound. Digitized sound and voice processing technology greatly improve the fidelity of sound, enriching the expressive power of music, which makes musical sound quality and music construct ability present unprecedented leap. Application and development of computer music is becoming increasingly popular in the business popularity world, which has a direct relationship with contemporary social cultural atmosphere in postmodern period. On the one hand, the professional becomes more and more detailed, and the degree of it becomes more and more high. While commercialization swept every corner of society, which makes the popular culture become the strongest voice of the era. On the other hand, since the electronic music successfully emerged in the business world and the popular music field in the 1960s, computer technology has developed further in the business application and popularization of music .its powerful functions and editing capabilities make it more like a duck to water in the cultural market .And many foreign music critics consider the computer music more as commercial music production.

When used in the dissemination of information, computer music technology mainly for the music production of decomposition and synthesis of the computer. Further audio processing will be done in this field, samly by means of computer, which seeks to break through the traditional forms of music and sound features, aimed to seek new sound designs, sound effects and musical expressions. From the perspective of music creation, it is a new way of composing, setting composer, playing, production at an organic whole, which can not only broaden the infinite possibilities of sound clips, also bring the dual audio experience for music. It can be said to be a special kind of music genres and types when using this approach to create music, owning its unique music style, language and aesthetic features. Differing from any other previous musical expressions ,this kind of music has its own characteristics and system, the reaction of the recipient to information dissemination caused by which is a revolutionary change especially in the melody, songs structure, harmony, orchestration, and other performances.

\section{IMPACT OF THE COMPUTER MUSIC TECHNOLOGY ON THE AUDIENCE MEMORY INFORMATION}

One view is supported by some scholars that it helps the audience memory information in the form of computer music to present vocabulary, which cannot be explained by a widely accepted mechanism. And scholars attributed the promotion role of music to the following aspects:

First, the music has its own structural features that can assist people to learn and memory the lyrics. Wallace (1994) believed that have been determining the length of the lyrics, setting the syllables whether be emphasized or not, and highlighting some of the specific elements of the lyrics, music as a framework made melody and lyrics closely work together to make every song as a coherent whole ${ }^{[3]}$. Other scholars believe that when the listeners are recalled the songs it is based on certain specific melody to fill into corresponding words. Therefore, the computer music is not just information, but a comprehensive and integrated framework, why it can assist people to learn and memory the lyrics.

Second, it has become slower to output information to the listener since the information can be presented in the form of computer music. In other words, it is the key factor in promoting memory that the pronunciation is slower to sing the language content than to say. Tests showed that it would do the same effect when the duration time in singing is controlled to be the same with speaking out the information content. This fully demonstrated that the key reason to learn and remember easily is the slower speed to sing than to say.

Third, most people like to listen to music or sing and repeatedly hum after hearing a song. It's just this fully exercises and repeat that play a significant promoting role on memory.

Another view is negative. Although it can help to remember information in the form of a song to present from a few aspects, many studies have shown that to say the language information is better than to sing to help listeners understand and remember information content ${ }^{[4]}$.The reason is that to say has more advantages than to sing on information transmission.

First, the listener may probably treat the lyrics from voice perspective rather than from the perspective of understanding the semantic meaning of the lyrics when by means of music to transfer information .Some scholars have found an interesting phenomenon in the experiment that the listener may sometimes replace the original words with phonetically similar words when recalled, for example when test subjects were recalled to replace the original text posterity by prosperity, which two words are phonetically similar but have very different semantics. Other researchers also reached a similar conclusion that the subjects sometimes replace the original word by the same number of syllables word when recalled, or replace by a meaningless | la | syllable when the word is missing in order to ensure the integrity of the song structure. All the above results have proved that although the melody provides a framework for learning language content, singing is a relatively shallow learning, the listener may probably treat the lyrics from voice perspective rather than from the perspective of understanding the semantic meaning of the lyrics.

Second, although the computer music is more abstract to well express feelings and render atmosphere, it has limited capacity of displaying the information logic and helping listeners deeply understand the semantics. While the language is more conducive for the listeners to do deep processing of information logic and semantics in order to express specific and identified information. In the way to say to present computer music to the listeners is more conducive if subjects 
consciously try to learn and remember the lyrics for the purpose. Therefore, in many studies, to say is more conducive to listeners to remember the lyrics than to sing.

\section{CONCLUSIONS AND IMPLICATIONS}

The computer music technology has played an important role in the production and dissemination of information, being an integral and important form in information dissemination, which has promoted the computer music technology move toward diversification trend. For information producers, the computer music technology has already become an important means of information production and dissemination. It has greatly enhanced the quality and efficiency of information production and dissemination that computer music technology continues to improve and the software and hardware keep constantly updated,which provide a scientific and effective music creation conditions for information dissemination workers so that the creation of music tend to be modern and digitized . But the computer music can only be as a technical means or compositional tools no matter how powerful it is in technology and how new the musical element is. Although the composer has mastered high tech hardware, been familiar with the computer music technology, the music still should only come from the heart rather than turning composing into a sound mind games relying on the way in technology. The production and dissemination of information do the same that the computer music technology can only be as a supplementary tool, with which the composer will become more efficient, and the information production and dissemination more colorful.

\section{ACKNOWLEDGEMENT}

Supported by the National Natural Science Foundation of China (Nos 71372099).

\section{LITERATURE REFERENCES}

[1] A. R. Kilgour, L. S. Jakobson and L. L. Cuddy, Music training and rate of presentation as mediators of text and song recall, J. Memory \& Cognition, 28 (2000) 700-710.

[2] S. L. Calvert, Impact of televised songs on children's and young adults' memory of educational content, J. Media Psychology, 3 (2001) 325-342.

[3] W. T. Wallace, Memory for music: Effect of melody on recall of text, J. Journal of Experimental Psychology: Learning, Memory, and Cognition, 20 (1994) 1471-1485.

[4] S. L. Calvert, R. L. Billingsley, Young children's recitation and comprehension of information presented by Songs, J. Journal of Applied Developmental Psychology, 19 (1998) 97-108.

[5] X Lin, Advertising slogan and analysis, Central South University Press, Changsha, 2007. 